NASA/TM-1999-206582

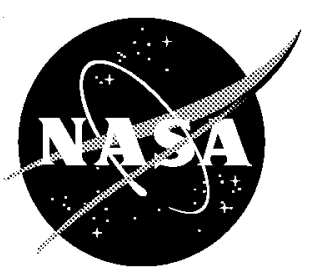

\title{
Reconfigurable Flight Control Designs With Application to the X-33 Vehicle
}

John J. Burken

Dryden Flight Research Center

Edwards, California

Ping Lu and Zhenglu $W u$

Iowa State University

Ames, Iowa 


\section{The NASA STI Program Office ... in Profile}

Since its founding, NASA has been dedicated to the advancement of aeronautics and space science. The NASA Scientific and Technical Information (STI) Program Office plays a key part in helping NASA maintain this important role.

The NASA STI Program Office is operated by Langley Research Center, the lead center for NASA's scientific and technical information. The NASA STI Program Office provides access to the NASA STI Database, the largest collection of aeronautical and space science STI in the world. The Program Office is also NASA's institutional mechanism for disseminating the results of its research and development activities. These results are published by NASA in the NASA STI Report Series, which includes the following report types:

- TECHNICAL PUBLICATION. Reports of completed research or a major significant phase of research that present the results of NASA programs and include extensive data or theoretical analysis. Includes compilations of significant scientific and technical data and information deemed to be of continuing reference value. NASA's counterpart of peer-reviewed formal professional papers but has less stringent limitations on manuscript length and extent of graphic presentations.

- TECHNICAL MEMORANDUM. Scientific and technical findings that are preliminary or of specialized interest, e.g., quick release reports, working papers, and bibliographies that contain minimal annotation. Does not contain extensive analysis.

- CONTRACTOR REPORT. Scientific and technical findings by NASA-sponsored contractors and grantees.
- CONFERENCE PUBLICATION.

Collected papers from scientific and technical conferences, symposia, seminars, or other meetings sponsored or cosponsored by NASA.

- SPECIAL PUBLICATION. Scientific, technical, or historical information from NASA programs, projects, and mission, often concerned with subjects having substantial public interest.

- TECHNICAL TRANSLATION. Englishlanguage translations of foreign scientific and technical material pertinent to NASA's mission.

Specialized services that complement the STI Program Office's diverse offerings include creating custom thesauri, building customized databases, organizing and publishing research results ... even providing videos.

For more information about the NASA STI Program Office, see the following:

- Access the NASA STI Program Home Page at http://www.sti.nasa.gov

- E-mail your question via the Internet to help@sti.nasa.gov

- Fax your question to the NASA Access Help Desk at (301) 621-0134

- Telephone the NASA Access Help Desk at (301) 621-0390

- Write to:

NASA Access Help Desk

NASA Center for AeroSpace Information 7121 Standard Drive

Hanover, MD 21076-1320 


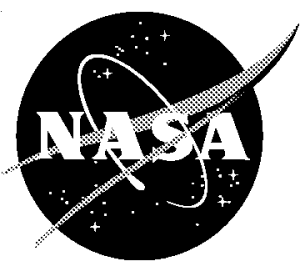

\section{Reconfigurable Flight Control Designs With Application to the X-33 Vehicle}

John J. Burken

Dryden Flight Research Center

Edwards, California

Ping Lu and Zhenglu $W u$

Iowa State University

Ames, Iowa

National Aeronautics and

Space Administration

Dryden Flight Research Center

Edwards, California 93523-0273 


\section{NOTICE}

Use of trade names or names of manufacturers in this document does not constitute an official endorsement of such products or manufacturers, either expressed or implied, by the National Aeronautics and Space Administration.

Available from the following:

NASA Center for AeroSpace Information (CASI)

7121 Standard Drive

Hanover, MD 21076-1320

(301) 621-0390
National Technical Information Service (NTIS) 5285 Port Royal Road Springfield, VA 22161-2171 (703) $487-4650$ 


\title{
RECONFIGURABLE FLIGHT CONTROL DESIGNS WITH APPLICATION TO THE X-33 VEHICLE
}

\author{
John J. Burken* \\ NASA Dryden Flight Research Center \\ Edwards, California \\ Ping $\mathrm{Lu}^{\dagger}$ \\ Zhenglu $\mathrm{Wu}^{+}$ \\ Iowa State University \\ Ames, Iowa
}

\begin{abstract}
$\underline{\text { Abstract }}$
Two methods for control system reconfiguration have been investigated. The first method is a robust servomechanism control approach (optimal tracking problem) that is a generalization of the classical proportional-plus-integral control to multiple inputmultiple output systems. The second method is a control-allocation approach based on a quadratic programming formulation. A globally convergent fixedpoint iteration algorithm has been developed to make onboard implementation of this method feasible. These methods have been applied to reconfigurable entry flight control design for the X-33 vehicle. Examples presented demonstrate simultaneous tracking of angle-of-attack and roll angle commands during failures of the right body flap actuator. Although simulations demonstrate success of the first method in most cases, the controlallocation method appears to provide uniformly better performance in all cases.

\section{Nomenclature}

A state plant matrix

b elements of $\mathbf{B}$

B control plant matrix

\footnotetext{
* Aerospace Engineer. Member AIAA. (661) 258-3726.

†Associate Professor, 304 Town Engineering Building, Department of Aerospace Engineering and Engineering Mechanics. Associate Fellow ALAA, Email: plu@iastate,edu.

Graduate Student, Department of Aerospace Engineering and Engineering Mechanics.

Copyright (C) 1999 by the American Institute of Aeronautics and Astronautics, Inc. No copyright is asserted in the United States under Title 17, U.S. Code. The U.S. Government has a royalty-free license to exercise all rights under the copyright claimed herein for Governmental purposes. All other rights are reserved by the copyright owner.
}

\begin{tabular}{|c|c|}
\hline c & controller \\
\hline $\mathbf{C}$ & state output matrix \\
\hline $\mathrm{CA}$ & control allocation \\
\hline $\mathrm{d}$ & disturbance vector \\
\hline$d_{x}$ & input to aircraft caused by jammed surface $w$ \\
\hline D & control output matrix \\
\hline e. & error \\
\hline $\mathbf{E}$ & disturbance (jammed surface) matrix \\
\hline $\mathbf{F}$ & output disturbance matrix \\
\hline $\mathrm{h}$ & elements of $\mathrm{H}$ \\
\hline $\mathrm{H}$ & arbitrary variable \\
\hline $\mathrm{i}$ & arbitrary integer \\
\hline I & identity matrix \\
\hline $\mathrm{j}$ & $\mathrm{j}^{\text {th }}$ component \\
\hline $\mathrm{J}$ & cost function \\
\hline $\mathbf{K}$ & gain \\
\hline 1 & 1 space; the vector space of all $n$ vectors \\
\hline $\mathrm{L}$ & lower \\
\hline $\mathrm{m}$ & $m$ space; the vector space of all $n$ vectors \\
\hline $\mathrm{n}$ & $\mathrm{n}$ space; the vector space of all $\mathrm{n}$ vectors \\
\hline $\mathrm{p}$ & $\mathrm{p}$ space; the vector space of all $\mathrm{n}$ vectors \\
\hline PI-servo & robust servomechanism design \\
\hline q & q order \\
\hline $\mathbf{Q}$ & weighting matrix \\
\hline$r$ & desired output \\
\hline $\mathrm{R}$ & real \\
\hline
\end{tabular}




\begin{tabular}{ll}
$\mathrm{s}$ & saturator \\
$t$ & time \\
$\mathrm{u}$ & control input vector \\
$\mathrm{u}_{\mathrm{r}}$ & remaining working control surface vector \\
$\mathrm{U}$ & upper \\
$v$ & velocity, ft/sec \\
$w$ & disturbance or position of jammed surface \\
$\mathrm{x}$ & state vector \\
$\mathrm{y}$ & output (observation) vector \\
$\mathrm{z}$ & output choice \\
$\alpha$ & angle of attack, deg \\
$\beta$ & sideslip angle, deg \\
$\gamma$ & elements of $\Gamma$ \\
$\Gamma$ & lower companion matrix form \\
$\delta$ & perturbation \\
$\delta_{l b f}$ & left body flap deflection, deg \\
$\delta_{l e v i}$ & left inboard elevon deflection, deg \\
$\delta_{l e v o}$ & left outboard elevon deflection, deg \\
$\delta_{l v r}$ & left vertical rudder deflection, deg \\
& \\
\hline &
\end{tabular}

$\begin{array}{ll}\delta_{r b f} & \text { right body flap deflection, deg } \\ \delta_{r e v i} & \text { right inboard elevon deflection, deg } \\ \delta_{\text {revo }} & \text { right outboard elevon deflection, deg } \\ \delta_{r r r} & \text { right vertical rudder deflection, deg } \\ \varepsilon & \text { near to zero as desired } \\ \zeta & \text { damping } \\ \eta & \text { scalar weighting } \\ \theta & \text { pitch angle, deg } \\ \lambda & \text { eigenvalues } \\ \phi & \text { roll angle, deg } \\ \varphi & \text { heading angle, deg }\end{array}$

\section{Introduction}

The X-33 vehicle is a one-half-scale suborbital prototype for the proposed single-stage-to-orbit reusable launch vehicle. In flight tests, the $X-33$ vehicle will accelerate to a maximum speed of Mach 13 and climb to an altitude of approximately $250 \mathrm{k} \mathrm{ft}$. The entry flight immediately follows a short transition phase after the ascent.

The X-33 vehicle (fig. 1) has four types of control surfaces: rudders $\left(\delta_{r i r}\right.$ and $\left.\delta_{l, r}\right)$, body flaps $\left(\delta_{r b f}\right.$

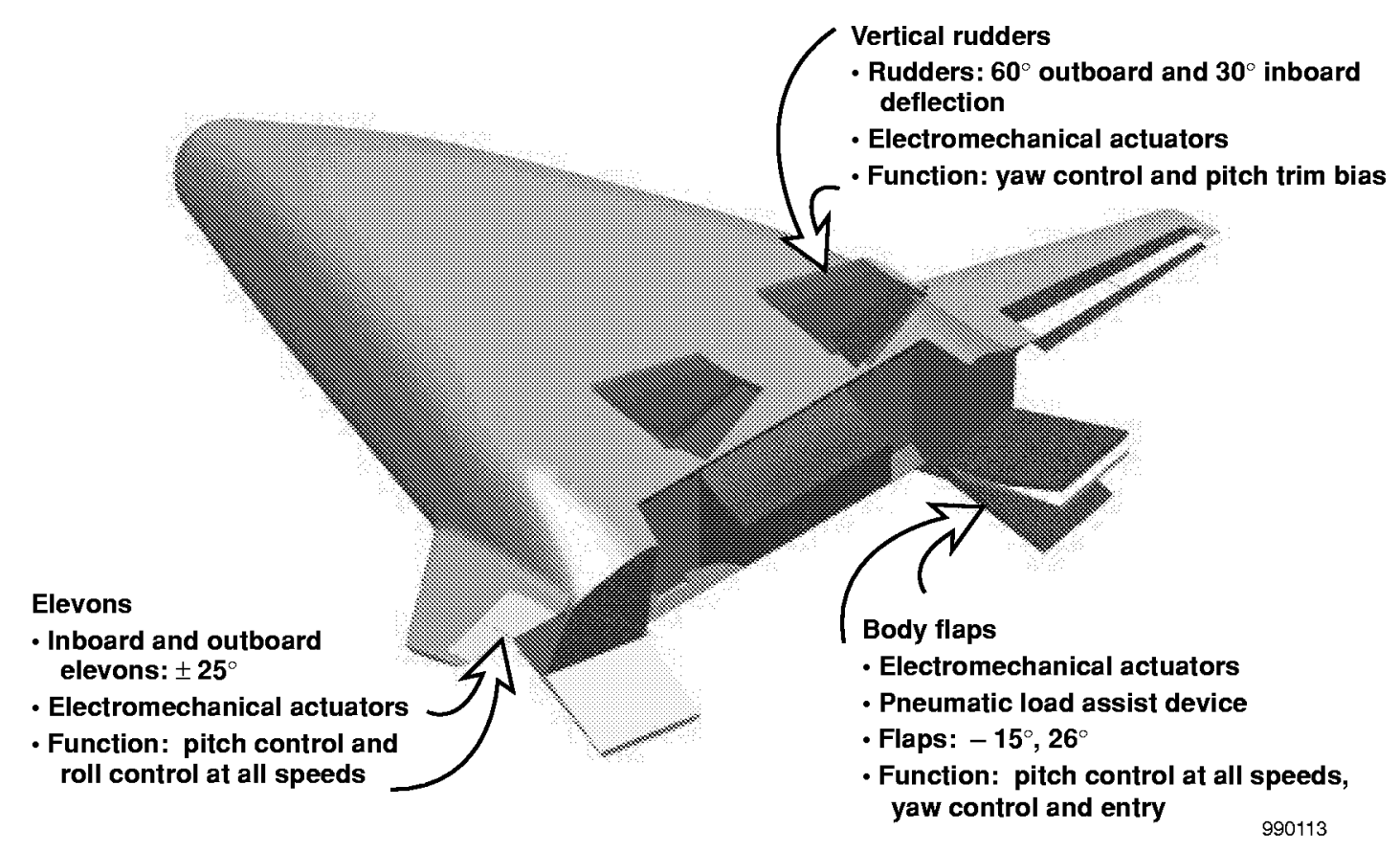

Figure 1. The X-33 vehicle. 
and $\left.\delta_{l b f}\right)$, and inboard $\left(\delta_{r e v i}\right.$ and $\left.\delta_{l e v i}\right)$ and outboard $\left(\delta_{\text {revo }}\right.$ and $\left.\delta_{\text {levo }}\right)$ elevons. Each of the eight surfaces can be independently actuated, with one actuator for each surface. All the aerosurfaces will use electromechanical actuators. The body flaps also have an pneumatic load assist device that can be used for a total of 40 sec during ascent or entry.

Analysis has shown that although the probability for an actuator failure is very low, when it does happen, the failure would most likely result in jamming (freezing) of the associated aerosurface. ${ }^{1}$ The eight control surfaces have control power capable of providing redundant pitch, roll, and yaw restoring moments such that if one surface fails, the potential exists for an alternate control scheme that will maintain control of the vehicle.

The control system problem statement for the $\mathrm{X}-33$ project is posed as this: If a single control surfaces fails (jams, floats, or runs away), can the nominal or reconfigurable controller be used to land the vehicle safely? The nominal controller has some inherent robustness and may be able to handle a limited failure set (such as a left rudder jammed at $3^{\circ}$ ). The reconfigurable controller should have a much larger region of survivable failure conditions.

Flight control system reconfiguration encompasses a set of methodologies concerned with making changes to adapt to system failures and damages. The adaptation can be in forms of control system gain changes or control law structure changes. Reconfigurable control offers the potential of significant enhancement of flight safety and mission success rate. Because of its clear benefits in both military and civil applications, flight control reconfiguration research has received considerable attention in recent years, exemplified by the U. S. Air Force Reconfigurable Control for Tailless Fighter Aircraft (RESTORE) program, ${ }^{2}$ flight test of the F-16 Variable Stability In-Flight Simulator Test Aircraft (VISTA), ${ }^{3}$ and the NASA X-33 program. $^{1}$ Reconfigurable control laws are baselined (onboard software) for the X-33 program. The references contained in reference 2 also provide a glimpse of some previous investigations on this subject.

Control reconfiguration consists of two main steps. The first step is failure detection and isolation that identifies where the failure occurs and to what extent. The second step involves adjusting the controller or control law to compensate for the failure. NASA has played an integral part in the development of the X-33 control laws, and as part of that effort, several reconfigurable control approaches have been developed and evaluated.
This research study focuses on the control law modification, assuming that the aircraft is fitted with smart actuators so that any locked control surfaces can be detected and the locked position identified if necessary. The objective of this work is to seek reconfigurable control system designs that are easily implementable in flight software, reliable, and offer assurance of flight safety and mission success for the targeted types of failures. The reconfigured control system is expected to maintain aircraft stability should a control surface failure occur, and to provide reasonable command-tracking performance.

Two reconfigurable approaches are investigated and evaluated in this paper. One is the robust servomechanism design (PI-servo), ${ }^{4,5}$ which is a generalization of the classical proportional-plus-integral design. In this approach, the effect of the jammed surface is treated as a disturbance to the system. The robust servomechanism controller is designed to stabilize the aircraft, balance the jammed surface (disturbance rejection), and provide command tracking.

The second approach is based on a control-allocation (CA) approach in which a satisfactory nominal control law is first designed for the healthy aircraft to produce the desired aircraft response. In the event of a jammed surface, the redundant degrees of freedom of the control effectors are used to distribute the deflections of the operable surfaces in an optimal way so as to cancel the influence of the jammed surface and reproduce, as closely as possible, the desired aircraft response to commands.

This paper presents results of applying these two reconfigurable methodologies to the X-33 entry flight. The first approach is simple to implement and able to stabilize and control the vehicle within the vehicle's capability to retrim in the presence of the jammed surface. The second approach requires slightly more onboard computation, but provides good, uniform performance.

The paper also reviews the methodology for the PI-servo and introduces the CA method and its quadratic programming problem. The Control-Allocation Reconfiguration section describes a fixed-point iteration algorithm suitable for onboard implementation for the associated quadratic programming problem. Results cover the application of the two methods to reconfigurable entry flight control of the X-33 vehicle and the evaluation of the performance. In the case of the PI-servo results, the nominal no-failure case is presented for further evaluation. Use of trade names or names of manufacturers in this document does not constitute an 
official endorsement of such products or manufacturers, either expressed or implied, by the National Aeronautics and Space Administration.

\section{Robust Servomechanism}

\section{$\underline{\text { Reconfigurable Design Problem }}$}

The PI-servo problem is concerned with control of a dynamic system to achieve asymptotic tracking of desired output states and rejection of unmeasurable disturbance(s). For single input-single output systems, the problem has been well-understood for 50 years. However, this problem has been solved for multiple input-multiple output systems only in the last two decades. In the following development, an alternate version of the problem is introduced and the controller design methodology is presented. ${ }^{3,4}$

\section{Problem Formulation}

Consider a linear, time-invariant, multiple inputmultiple output system,

$$
\begin{gathered}
\dot{x}=\mathbf{A x}+\mathbf{B u}+\mathbf{E} w \text { and } \\
y=C x+D u+F w
\end{gathered}
$$

where $x \in R^{n}$ is the plant state vector, $u \in R^{m}$ is the plant input vector, $w \in \mathrm{R}^{1}$ is the disturbance vector, and $\mathrm{y} \in \mathrm{R}^{\mathrm{p}}$ is the controlled output with $\mathrm{p} \leq \mathrm{m}$. Let $r \in \mathrm{R}^{\mathrm{p}}$ represent the desired output. The problem of control surface failure can be considered in the framework through the $w$ vector. Specifically, $w$ represents the input resulting from any one surface failed at a given position. Assume $r$ and $w$ are continuously differentiable $q$ times, and the real scalers $\alpha$ and $q$ exist such that:

$$
\begin{aligned}
& r^{(\mathrm{q})}+\alpha_{1} r^{(\mathrm{q}-1)}+\ldots+\alpha_{\mathrm{q}-1} \dot{r}+\alpha_{\mathrm{q}} r=0 \text { and } \\
& w^{(\mathrm{q})}+\alpha_{1} w^{(\mathrm{q}-1)}+\ldots+\alpha_{\mathrm{q}-1} \dot{w}+\alpha_{\mathrm{q}} w=0,
\end{aligned}
$$

with $q \geq 1$. Note that the above formulation encompasses many commonly used signal forms, including constants (when $q=1$ and $\alpha_{i}=0$ ); polynomials (when $\alpha_{i}=0, \mathrm{i}=1, \ldots \mathrm{q}$ ); sinusoidal functions (when $q=2, \alpha_{1}=0$ and $\alpha_{2}>0$ ); and exponential functions. The initial conditions for $w$ are assumed to be arbitrary; therefore, $w(t)$ is considered unknown (immeasurable). In a general formulation, the dynamics of $r(t)$ and $w(t)$ do not have to be the same, ${ }^{5}$ but for simplicity, they are assumed to be the same here (which is adequate for the subject of this paper). The objective of the control design is to find a feedback controller such that:

- the closed-loop system is stable.

- the error $e(t)=r(t)-\mathrm{y}(t)$ approaches 0 , as time goes to infinity, in the presence of the immeasurable disturbance $w(t)$.

- the closed-loop system is robust in the sense that as long as the system remains stable, asymptotic tracking of $r$ and rejection of $w$ are maintained in the presence of system parametric uncertainty or even variations in the order of the dynamics.

\section{Robust Servomechanism Design Methodology}

A dynamic controller will be designed to meet the above stated objectives. The controller dynamics are set to be

$$
\dot{\mathrm{x}}_{\mathrm{c}}=\mathbf{A}_{\mathrm{c}} \mathrm{x}_{\mathrm{c}}+\mathbf{B}_{\mathrm{c}}(r-\mathrm{y})
$$

where $\mathrm{x}_{\mathrm{c}} \in \mathrm{R}^{\mathrm{pq}}$ is the controller state, and $\mathbf{A}_{\mathrm{c}} \in \mathrm{R}^{\mathrm{pq} \times \mathrm{pq}}=$ block diag $[\Gamma, \ldots, \Gamma]$ with

$$
\Gamma=\left[\begin{array}{ccccc}
0 & 1 & 0 & \ldots & 0 \\
0 & 0 & 1 & \ldots & 0 \\
\vdots & \vdots & \vdots & \vdots & \vdots \\
0 & 0 & \ldots & 0 & 1 \\
-\alpha_{\mathrm{q}} & -\alpha_{\mathrm{q}-1} & \ldots & -\alpha_{2} & -\alpha_{1}
\end{array}\right] \in \mathrm{R}^{\mathrm{q} \times \mathrm{q}}
$$

and $\mathbf{B}_{\mathrm{c}} \in \mathrm{R}^{\mathrm{pq} \times \mathrm{q}}=\operatorname{block} \operatorname{diag}[\gamma, \ldots, \gamma]$ with

$$
\gamma=\left[\begin{array}{c}
0 \\
\vdots \\
0 \\
1
\end{array}\right] \in \mathrm{R}^{\mathrm{q}}
$$

Consider the open-loop system including the plant (eq. (1)) and the controller dynamics (eq. (5)):

$$
\left[\begin{array}{c}
\dot{x} \\
\dot{x}_{c}
\end{array}\right]=\left[\begin{array}{cc}
\mathbf{A} & 0 \\
-\mathbf{B}_{c} \mathbf{C} & \mathbf{A}_{\mathrm{c}}
\end{array}\right]\left[\begin{array}{c}
\mathrm{x} \\
\mathrm{x}_{\mathrm{c}}
\end{array}\right]+\left[\begin{array}{c}
\mathbf{B} \\
-\mathbf{B}_{\mathrm{c}} \mathbf{D}
\end{array}\right] \mathrm{u} .
$$

Let $\lambda_{1}, \ldots, \lambda_{\mathrm{q}}$ be the roots of the polynomial

$$
\lambda^{\mathrm{q}}+\alpha_{1} \lambda^{\mathrm{q}-1}+\ldots+\alpha_{\mathrm{q}-1} \lambda+\alpha_{\mathrm{q}}=0
$$

If the following condition is satisfied: 


$$
\operatorname{rank}\left[\begin{array}{cc}
\lambda_{\mathrm{i}} \mathbf{I}-\mathbf{A} & \mathbf{B} \\
-\mathbf{C} & \mathbf{D}
\end{array}\right]=\mathbf{n}+\mathrm{p}, \mathrm{i}=1, \ldots, \mathrm{q},
$$

then the augmented system (eq. (8)) is controllable. ${ }^{4,5}$ Hence, a control law

$$
\mathrm{u}=k \mathrm{x}+k_{\mathrm{c}} \mathrm{x}_{\mathrm{c}}
$$

exists such that the closed-loop system is stable. Furthermore, for any such control law, asymptotic tracking and disturbance rejection are achieved; that is, $e=r-\mathrm{y} \rightarrow 0$ for any initial condition $\mathrm{x}(0)$ and any $w$ satisfying equation (4). The closed-loop system possesses robustness in that for any perturbations in $\left\{\mathbf{A}, \mathbf{B}, \mathbf{C}, \mathbf{D}, \mathbf{B}_{\mathrm{c}}, k, k_{\mathrm{c}}\right\}$, asymptotic tracking and disturbance rejection still hold as long as the closed-loop system remains stable and $\mathbf{B}_{\mathrm{c}}$ remains block diagonal. ${ }^{4,5}$

The following remarks are applicable for this derivation:

- If the augmented system (eq. (8)) is controllable, the control law (eq. (10)) can be conveniently found by applying the linear quadratic regulator approach to equation (8).

- In the special case where $r$ is constant command and $w$ is constant (but possibly unknown) disturbance, $q=1$ and $\alpha_{1}=0$. Therefore, $\boldsymbol{A}_{c}=0$ and $\mathbf{B}_{\mathrm{c}}=\mathbf{I}_{\mathrm{p} \times \mathrm{p}}$ according to their definitions. The controller dynamics (eq. (5)) show that $\mathrm{x}_{\mathrm{c}}=\int(r-y) \mathrm{d} t=\int e \mathrm{~d} t$. Thus, the control law (eq. (10)) is simply a proportional-plus-integral control law, which is well-known in classical single input-single output control theory. But the current formulation is much more general in that it applies to multiple input-multiple output systems and allows tracking of time-varying commands and rejection of disturbances.

- This PI-servo conveniently applies to control of impaired aircraft with one or more jammed control surfaces. Suppose that the dynamic model (eq. (1)) represents the linearized dynamics of such an aircraft at a trim condition. Let $w$ in equation (1) denote the (constant) position of the jammed surface, and $\mathrm{u}$ denote all the remaining operable surfaces (the exact value of $w$ does not need to be known with this method). The matrix $\mathbf{E}$ (a column vector in this case) is then the control derivatives associated with the surface now jammed (or equivalently, the column corresponding to the jammed surface in the $\mathbf{B}$ matrix of the linearized model prior to failure). Now the problem is cast into the formulation in the previous section and a proportional-plus-integral controller (eq. (10)) can be designed by linear quadratic regulator or pole-placement methods to stabilize the aircraft, reject the influence of the jammed surface, and track commands. References 3 and 4 provide more complete discussion and detail.

\section{Control-Allocation Reconfiguration}

Control allocation is concerned with distributing the deflection commands of multiple control surfaces of the aircraft to generate required control responses (for example, pitch, roll, and yaw moments) when the number of independent control surfaces is greater than the number of required independent control responses. Reference 6 contains a list of recent work on CA and provides several additional approaches to $\mathrm{CA}$ based on quadratic and linear programming.

\section{Problem Formulation}

In this section, a control reconfiguration approach based on a CA scheme using the quadratic programming method is considered. The intent is to use the redundancy of the operable control surfaces to compensate for the effects of the jammed surface and still provide the same (or almost the same) desired control responses. Clearly, the greater the control redundancy is, the better suited this approach would be. This approach requires the position of the jammed surface to be known, either through the use of smart actuator or by estimation.

Let the linearized dynamics of the normal aircraft at a trim condition be given by

$$
\dot{\mathrm{x}}=\mathbf{A x}+\mathbf{B u} .
$$

A nominal control law is assumed to have been designed based on the model of equation (11) that provides satisfactory stabilization and commandtracking performance for the aircraft. Suppose now that one of the control surfaces is suddenly jammed at a position $w$. Rewrite the postfailure state equation of the system (eq. (11)) as

$$
\dot{\mathrm{x}}=\mathbf{A x}+\mathbf{B}_{r} \mathbf{u}_{\mathrm{r}}+d_{x},
$$

where $\mathrm{u}_{\mathrm{r}} \in \mathrm{R}^{\mathrm{m}}$ represents the remaining control surfaces, $d_{x} \in \mathrm{R}^{\mathrm{n}}$ denotes the input to the aircraft caused by the jammed surface $w$, and $d_{x}$ is known when $w$ is known. The variable $d_{x}$ is the product of the 
jammed surface position times the control power $\mathbf{B}_{\mathrm{d}} w$; in other words, the column(s) of $\mathbf{B}$ represent the damaged control times the magnitude of the jammed position. Let $\mathrm{z}=\mathrm{C}_{\mathrm{z}} \mathrm{x}$ be a selected $\mathrm{i}$-dimensional output vector $\left(z \in R^{i}\right)$ to be used in defining the control allocation, and

$$
\dot{\mathrm{z}}=\mathbf{C}_{\mathrm{z}} \mathbf{A x}+\mathbf{C}_{\mathrm{z}} \mathbf{B}_{r} \mathrm{u}_{\mathrm{r}}+\mathbf{C}_{\mathrm{z}} d_{x} \triangleq \mathbf{A}_{\mathrm{z}} \mathrm{x}+\mathbf{B}_{\mathrm{z}} \mathrm{u}_{\mathrm{r}}+\mathrm{d}_{\mathrm{z}}
$$

The choice of $z$ is not necessarily the same as $y$ in the Robust Servomechanism Reconfigurable Design Problem section, but one that specifies the required performance. For instance, one most natural choice of $\mathrm{z}$ is $\mathrm{z}=(\mathrm{p} r \mathrm{q})^{T}$ (the roll, yaw, and pitch rates). Other choices are also possible, provided the resulting $\mathbf{B}_{\mathrm{z}}$ matrix has no zero rows. In general, $m$ is required to be greater than or equal to $i$ in this approach (that is, the number of operable control surfaces is greater than that of the controlled variables). At the current state $\mathrm{x}(t)$, suppose that the nominal control law would have produced $\mathbf{u}^{*} \in \mathrm{R}^{\mathrm{m}+1}$. Then the desired rate of $\mathrm{z}$ would be $\dot{z}^{*}=\mathbf{C}_{\mathrm{z}} \mathbf{A x}+\mathbf{C}_{\mathbf{z}} \mathbf{B} u^{*}$. A $\mathbf{u}_{\mathrm{r}}$ is sought that makes $\mathbf{B}_{\mathrm{z}} \mathrm{u}_{\mathrm{r}}+\mathrm{d}_{\mathrm{z}}$ as close as possible to $\mathbf{C}_{\mathrm{z}} \mathbf{B} \mathbf{u}^{*}$. Thus, the actual $\dot{z} \approx \dot{z}^{*}$; hence, $\mathrm{z}$ remains close to $\mathrm{z}^{*}$, which represents desired performance. Such a $u_{r}$ can be determined by minimization of the following quadratic function,

$$
\begin{aligned}
\min _{\mathrm{u}_{\mathrm{r}}} \mathrm{j}= & \frac{1}{2}\left[(1-\varepsilon)\left(\mathbf{B}_{\mathrm{z}} \mathbf{u}_{\mathrm{r}}+\mathrm{d}_{\mathrm{z}}-\mathbf{C}_{\mathrm{z}} \mathbf{B} \mathrm{u}^{*}\right)^{T} \mathbf{Q}_{1}\right. \\
& \left.\times\left(\mathbf{B}_{\mathrm{z}} \mathbf{u}_{\mathrm{r}}+\mathrm{d}_{\mathrm{z}}-\mathbf{C}_{\mathrm{z}} \mathbf{B} \mathbf{u}^{*}\right)+\varepsilon \mathbf{u}_{\mathrm{r}}^{T} \mathbf{Q}_{2} \mathrm{u}_{\mathrm{r}}\right]
\end{aligned}
$$

for some small $0<\varepsilon<1$; and subject to

$$
\mathrm{u}_{\mathrm{rmin}} \leq \mathrm{u}_{\mathrm{r}} \leq \mathrm{u}_{\mathrm{rmax}}
$$

where $\mathbf{Q}_{1}$ and $\mathbf{Q}_{2}$ are positive definite matrices of appropriate dimensions. The $u_{r m i n}$ and $u_{r m a x}$ are the lower and upper bounds of the remaining control surfaces.

The minimization of $\mathrm{J}$ subject to equation (15) constitutes a quadratic programming problem. The term $\varepsilon \mathrm{u}_{\mathrm{r}}^{T} \mathrm{Q}_{2} \mathrm{u}_{\mathrm{r}}$ in equation (14) is a regularization term to the quadratic programming problem. Without the term $(\varepsilon=0)$, the Hessian of $\mathrm{J}, \partial^{2} \mathrm{~J} / \partial \mathrm{u}_{\mathrm{r}}^{2}=$ $\mathbf{B}_{\mathrm{z}}^{T} \mathbf{Q}_{1} \mathbf{B}_{\mathrm{z}} \in \mathrm{R}^{\mathrm{m} \times \mathrm{m}}$, is not strictly positive definite because the rank of $B_{z}^{T} Q_{1} B_{z} \in R^{m \times m}$ is at most $i$, but $\mathrm{m}>\mathrm{i}$. In this case, the quadratic programming problem has no unique solution, and consequently chattering in $\mathrm{u}_{\mathrm{r}}$ can easily occur. Conversely, any $0<\varepsilon<1$ will make the Hessian of $J$ positive definite and the solution to the quadratic programming problem is unique. But clearly $\varepsilon$ should be sufficiently small in order for $\mathbf{B}_{\mathrm{z}} \mathrm{u}_{\mathrm{r}}+\mathrm{d}_{\mathrm{z}}-\mathbf{C}_{\mathrm{z}} \mathbf{B} \mathbf{u}^{*} \approx 0$. When $\mathbf{B}_{\mathrm{z}} \mathbf{u}_{\mathrm{r}}+\mathbf{d}_{\mathrm{z}}-\mathbf{C}_{\mathrm{z}} \mathbf{B} \mathbf{u}^{*} \approx 0$, the response of the aircraft would be very close to that of the healthy aircraft, despite the jamming of a control surface.

\section{Fixed-Point Algorithm}

A reliable, efficient, and simple algorithm is necessary for this CA approach to be useful in practice. When none of the constraints in equation (15) is active, solving the quadratic programming problem is straightforward. The solution $u_{r}$ is obtained from the unique solution of the linear algebraic system $\partial \mathrm{J} / \partial \mathrm{u}_{\mathrm{r}}=0$, which gives

$$
\begin{array}{r}
\mathrm{u}_{\mathrm{r}}=(1-\varepsilon)\left[(1-\varepsilon) \mathbf{B}_{\mathrm{z}}^{T} \mathbf{Q}_{1} \mathbf{B}_{\mathrm{z}}+\varepsilon \mathbf{Q}_{2}\right]^{-1} \\
\mathbf{B}_{\mathrm{z}}^{T} \mathbf{Q}_{1}\left(\mathbf{C}_{\mathrm{z}} \mathbf{B} \mathrm{u}^{*}-\mathrm{d}_{\mathrm{z}}\right) .
\end{array}
$$

In general cases where some of the constraints in equation (15) are active, the standard quadratic programming algorithms ${ }^{7}$ are involved and not suited for onboard implementation and applications. Equation (15) is a box constraint and requires more computational power. But for the special class of quadratic programming problems such as in equations (14) and (15) where only inequality constraints of the simple form ((eq. 15)) exist, an extremely simple, globally convergent fixed-point iteration algorithm can be devised for onboard use. This method is described and used in reference 7 in a different context. This method is applied to the quadratic programming problem (eqs. (14) and (15)).

Define a vector saturator $\mathrm{s}[\cdot]=\left(\mathrm{s}_{1}[\cdot] \ldots \mathrm{s}_{\mathrm{m}}[\cdot]\right)^{T}$ : $\mathrm{R}^{\mathrm{m}} \rightarrow \mathrm{R}^{\mathrm{m}}$ by

$$
\mathrm{s}_{\mathrm{j}}[\zeta]= \begin{cases}\mathrm{U}_{\mathrm{j}}, & \zeta_{\mathrm{j}} \geq \mathrm{U}_{\mathrm{j}} \\ \zeta_{\mathrm{j}}, & \mathrm{L}_{\mathrm{j}}<\zeta_{\mathrm{j}}<\mathrm{U}_{\mathrm{j}}, \quad \mathrm{j}=1,2, \ldots, \mathrm{m} \\ \mathrm{L}_{\mathrm{j}}, & \zeta_{\mathrm{j}} \leq \mathrm{L}_{\mathrm{j}}\end{cases}
$$

for any $\zeta=\left(\zeta_{1} \ldots \zeta_{\mathrm{m}}\right)^{T} \in \mathrm{R}^{\mathrm{m}}$, where for the moment $\mathrm{U}_{\mathrm{j}}=\mathrm{u}_{\max _{\mathrm{j}}}$, and $\mathrm{L}_{\mathrm{j}}=\mathrm{u}_{\min _{\mathrm{j}}}$, set to be equal to the upper and lower bound or the $\mathrm{j}^{\text {th }}$ component of $\mathrm{u}_{\mathrm{r}}$, respectively. Let $H=(1-\varepsilon) \mathbf{B}_{\mathrm{z}}^{T} \mathbf{Q}_{1} \mathbf{B}_{\mathrm{z}}+\varepsilon \mathbf{Q}_{2}$. Calculate the scalar 


$$
\eta=\left[\sum_{i=1}^{m} \sum_{j=1}^{m} h_{i j}^{2}\right]^{-1 / 2},
$$

where $h_{i j} s$ are the elements of $H$. Then the solution to the quadratic programming problem satisfies the following fixed-point equation:

$$
\begin{aligned}
& \mathbf{u}_{\mathrm{r}}=\mathrm{s}\left[(1-\varepsilon) \eta \mathbf{B}_{\mathrm{z}}^{T} \mathbf{Q}_{1}\left(\mathbf{C}_{\mathrm{z}} \mathbf{B} \mathbf{u}^{*}-\mathrm{d}_{\mathrm{z}}\right)\right. \\
& \left.-\left(\eta \mathrm{H}-\mathbf{I}_{\mathrm{m} \times \mathrm{m}}\right) \mathrm{u}_{\mathrm{r}}\right] \triangleq
\end{aligned}
$$

Furthermore, the fixed-point iteration

$$
\mathbf{u}_{\mathrm{r}}^{(k)}=f\left(\mathrm{u}_{\mathrm{r}}^{(k-1)}\right), k=1,2, \ldots, \forall \mathrm{u}_{\mathrm{r}}^{(0)} \in \mathrm{R}^{\mathrm{m}}
$$

converges to the unique solution of the quadratic programming problem from any initial guess $u_{r}^{(0)}$.

Note that the unconstrained solution (eq. (16)) is just a special case of equation (19) when none of the components of the saturator $s$ in equation (19) is active. In such a case, $s[\zeta]=\zeta$; therefore, equation (19) simply reduces to equation (16).

The fixed-point iteration algorithm (eq. (20)) is particularly suited for onboard implementation. If the initial guess $u_{r}^{(0)}$ is chosen to be the solution of the quadratic programming problem in the previous control update cycle, the current $u_{\mathrm{r}}$ should be obtained in just a few iterations from equation (20).

A similar constrained optimization problem was formulated in reference 2 for redistributing control surfaces after a hardware failure. Although simulations showed good performance, the computation requirement using a standard algorithm was deemed to be too intensive for onboard implementation. The control system commands could not be guaranteed before the next update cycle was required for the flight control computer. These concerns appear to be satisfactorily addressed by the current algorithm.

Note that this method accommodates both control surface amplitude and rate constraints. Suppose that the sampling time of the control system is $\Delta t$ and the rate limit for the $\mathrm{j}^{\text {th }}$ surface is $\dot{\mathrm{u}}_{\text {max }_{\mathrm{j}}}$, in addition to the amplitude constraint (eq. (15)). ${ }^{8}$ The only modifications will be to redefine the bounds of the saturator (eq. (17)) at each $t$ by

$$
\begin{aligned}
& \mathrm{U}_{\mathrm{j}}=\min \left\{\mathrm{u}_{\max _{\mathrm{j}}}, \mathrm{u}_{\max _{\mathrm{j}}} \Delta t+\mathrm{u}_{\mathrm{j}}(t-\Delta t)\right\} \\
& \mathrm{L}_{\mathrm{j}}=\max \left\{\mathrm{u}_{\min _{\mathrm{j}}},-\mathrm{u}_{\max _{\mathrm{j}}} \Delta t+\mathrm{u}_{\mathrm{j}}(t-\Delta t)\right\},
\end{aligned}
$$

where $\mathrm{u}_{\mathrm{j}}(t-\Delta t)$ is the calculated control command for $\mathrm{u}_{\mathrm{j}}$ at the previous update.

\section{Reconfigurable Entry Flight Control Designs for the $\mathrm{X}-33$ Vehicle}

As previously mentioned, the $\mathrm{X}-33$ vehicle is a onehalf-scale suborbital prototype for the proposed singlestage-to-orbit reusable launch vehicle proposed by Lockheed Martin Corporation (Burbank, California) that will be called the VentureStar. In flight tests, the X-33 vehicle will accelerate to a maximum speed of Mach 13 and climb to an altitude of approximately $250 \mathrm{kft}$ (fig. 1). The X-33 vehicle relies on engine thrust vectoring and aerosurfaces during the ascent phase. During the entry phase, the $X-33$ vehicle will be controlled by aerosurfaces and reaction control jets.

During the ascent phase, only marginal benefits of reconfiguration were shown because the corrective forces of which the engine thrust vectoring is capable can overcome any failed surface position. This study presents results from the entry phase because reconfiguration has been shown to have the greatest payoff or benefits during entry. The appendix provides the linearized dynamic model and related trim conditions of the X-33 vehicle at the critical entry condition of Mach 3.13. This operating point will be used to demonstrate the two design approaches introduced in preceding sections because this flight condition is a critical, unstable lateral-directional point.

Both the longitudinal and lateral-directional time histories will be shown because of coupling between axes following a surface failure. The plots show absolute control surface values (not the perturbation results). The analysis was performed using the Simulink ${ }^{\circledR}$ software (The MathWorks, Inc., Natick, Massachusetts). ${ }^{9}$

\section{Determination of Trimmable Jam}

Before proceeding with the reconfigurable control design, determining whether the aircraft can still be retrimmed with a particular aerosurface jammed at a given position is helpful. Rewrite the postfailure aircraft model as

$$
\dot{\mathrm{x}}=\mathrm{Ax}+\mathrm{B}_{r} \mathrm{u}_{\mathrm{r}}+\mathrm{b}_{\delta} \delta,
$$


where (as before) $\delta$ is the jammed surface position, $\mathbf{B}_{r}$ is the postfailure $\mathbf{B}$ matrix, $\mathbf{u}_{\mathbf{r}}$ is the remaining control surfaces, and $b_{\delta}$ is the sensitivity vector corresponding to the jammed surface. Let $\dot{y} \in \mathrm{R}^{3}$ represent the three body angular (roll, yaw, and pitch) rates of the vehicle, and $\dot{\mathrm{y}}=\mathbf{C}_{r} \mathrm{x}$. Clearly,

$$
\dot{\mathrm{y}}=\mathrm{C}_{r} \mathrm{Ax}+\mathrm{C}_{r} \mathbf{B}_{r} \mathrm{u}_{\mathrm{r}}+\mathrm{C}_{r} \mathrm{~b}_{\delta} \delta
$$

To find the range of jammed positions of the surface $\delta$ for which retrimming is possible, solve the following linear programming problem:

$$
\min _{\mathrm{u}_{\mathrm{r}}, \delta} \delta \quad\left(\text { or } \max _{\mathrm{u}_{\mathrm{r}}, \delta} \delta\right)
$$

subject to

$$
\begin{gathered}
\mathbf{C}_{r} \mathbf{B}_{r} \mathbf{u}_{\mathrm{r}}+\mathbf{C}_{r} \mathbf{b}_{\delta} \delta=0 \\
\mathrm{u}_{\min } \leq \mathrm{u} \leq \mathrm{u}_{\max },
\end{gathered}
$$

where $\mathbf{u}=\left(\mathrm{u}_{\mathrm{r}}^{T} \delta\right)^{T}$. The solution of the linear programming problem (eqs. (25)-(27)) gives the minimum (most negative) or maximum jammed position of $\delta$ that can be balanced, from the trim condition, by the remaining aerosurfaces $u_{r}$ within their deflection limits. The perturbation values must be added to the trim surface positions for absolute aerosurface limit constraints. This range bounds the limits within which the reconfigurable control system can still possibly stabilize the vehicle.

Applying this technique to the $\mathrm{X}-33$ model in the appendix, engineers found that for any jammed position within the physical limits of all aerosurfaces except the flaps, the vehicle can potentially be retrimmed. For a jammed body flap, however, retrimming was found to be only possible between $\delta_{\min }=-8.74^{\circ}$ and $\delta_{\max }=8.46^{\circ}$ because the body flaps are the dominant aerosurfaces for pitch control, and other aerosurfaces cannot adequately compensate for one of the flaps jammed at a position far from the trim position. The $\delta$ values must be added to the trim values to obtain the absolute values.

The aircraft not only has to be trimmable but must also be maneuverable and controllable. Therefore, when commands need to be tracked, the range of trimmable body flap jammed positions (for which reconfiguration is possible) will be even smaller than the range found above because tracking of the commands requires additional deflections of the remaining aerosurfaces.

\section{$\underline{\text { Robust Servomechanism Design Results }}$}

Following the method in the Robust Servomechanism Reconfigurable Design Problem section, engineers can design a PI-servo reconfigured control system for each jammed surface. The three outputs chosen to be commanded are roll angle, $\phi$, sideslip angle, $\beta$, and angle of attack, $\alpha$.

The $\beta$ command is normally $0^{\circ}$ for coordinated flight. Although the linearized longitudinal and lateraldirectional dynamics are decoupled in the system matrix A, all the control surfaces contribute to both longitudinal and lateral dynamics to different extents. Therefore, the control design is carried out simultaneously for both longitudinal and lateral modes. In design of the feedback proportional-plus-integral control law, the forward velocity is ignored because it has negligible effect on the response. Assume constant commands $\phi_{\mathrm{cmd}}$, $\beta_{\mathrm{cmd}}$, and $\alpha_{\mathrm{cmd}}$. With $\mathrm{y}=(\phi \beta \alpha)^{T}$ and $r=\left(\phi_{\text {cmd }} \beta_{\text {cmd }} \alpha_{\text {cmd }}\right)^{T}$, the controller dynamics (eq. (5)) are now

$$
\begin{aligned}
& \dot{x}_{\mathrm{c} 1}=\phi_{\mathrm{cmd}}-\phi \\
& \dot{\mathrm{x}}_{\mathrm{c} 2}=\beta_{\mathrm{cmd}}-\beta \\
& \dot{\mathrm{x}}_{\mathrm{c} 3}=\alpha_{\mathrm{cmd}}-\alpha .
\end{aligned}
$$

For each jammed surface, the remaining seven surfaces and the eight vehicle states (excluding the forward velocity) plus the three integrator states (eq. (28)) constitute the augmented system (eq. (8)). This augmented system is controllable. A linear quadratic regulator control law for the augmented system, which is a proportional-plus-integral control law for the $\mathrm{X}-33$ vehicle in the form of

$$
\begin{aligned}
\mathrm{u}_{\mathrm{r}}= & \mathrm{K}_{\mathrm{x}} \mathrm{x}+k_{\phi} \int\left(\phi_{\mathrm{cmd}}-\phi\right) \mathrm{d} t \\
& +k_{\beta} \int\left(\beta_{\mathrm{cmd}}-\beta\right) \mathrm{d} t+k_{\alpha} \int\left(\alpha_{\mathrm{cmd}}-\alpha\right) \mathrm{d} t,
\end{aligned}
$$

can be easily designed, where $\mathrm{x}=(\mathrm{p} r \beta \phi \varphi \alpha \mathrm{q} \theta)^{T}$. Engineers have found that for any single jammed surface except the flaps, a single set of gains is adequate to handle any jammed position within the deflection limits. No scheduling of the gains with respect to the jammed position is necessary (from Mach 10.0 to Mach 0.3 ). For a jammed flap in the range of $\left[-8.7^{\circ}, 8.5^{\circ}\right]$, a single set of 
gains are adequate for stabilizing (retrimming) the X-33 vehicle. With command tracking, the body flap range is small, depending on the amplitudes of the commands because of rate and surface saturation. This range cannot be increased by any gain scheduling with respect to the jammed flap position because this range is the physical limit for the $\mathrm{X}-33$ vehicle to retrim because of the large aerodynamic effectiveness of the body flap for which reconfiguration must compensate.

Figures 2-4 show the time histories of the failure case of a runaway left inboard elevon that starts at $t=0$ and jams at $-15^{\circ}$. A longitudinal and lateral-directional guidance command tracking step input starts at $t=1$. The guidance commands are for simultaneous tracking of angle-of-attack and roll angle commands during the failure because maneuvers in both axes are demanding of the reconfigurable control system. Sideslip angle command remains at $0.0^{\circ}$ for all the test cases. Figure 2 shows the commands and the resulting responses. The PI-servo controller tracks the commanded angle of attack of $8^{\circ}$ and the roll angle of $10^{\circ}$ well. Figure 3 shows the left surface positions and figure 4 shows the right surface positions plotted.
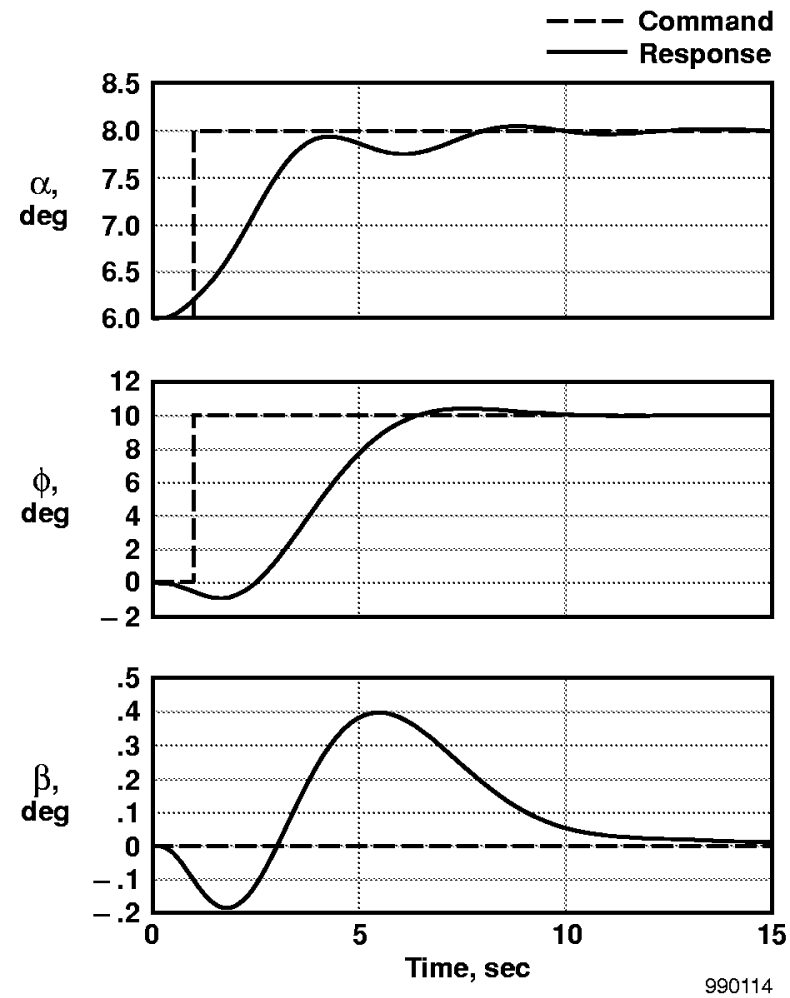

Figure 2. X-33 response using the PI-servo method with left inboard elevon jammed at $-15^{\circ}$.
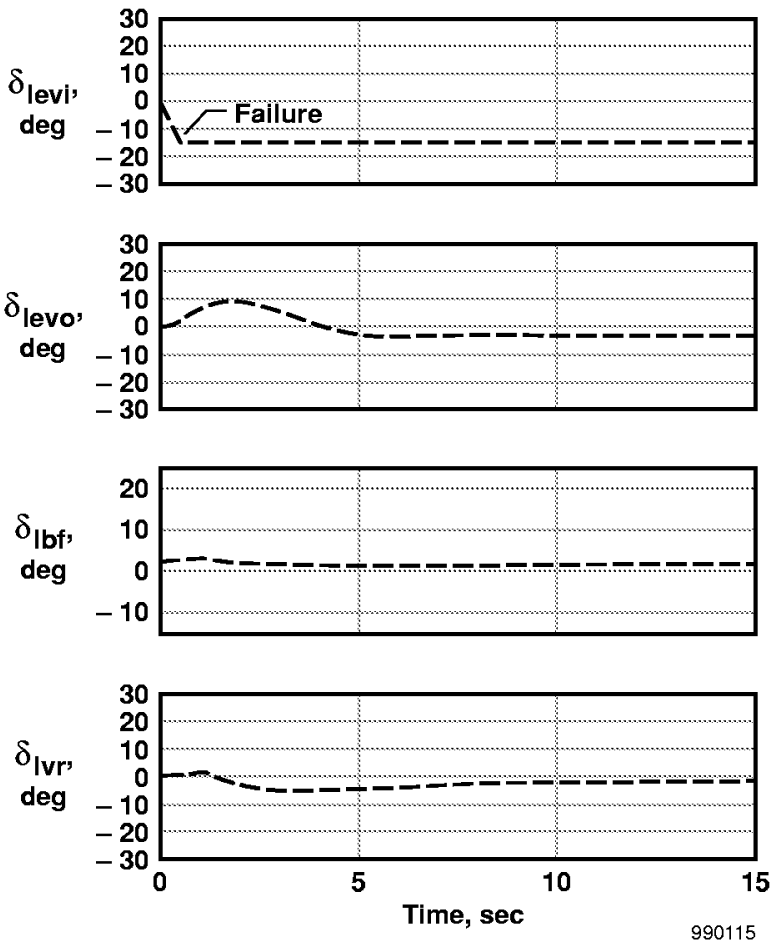

Figure 3. X-33 surface deflections using the PI-servo method with left inboard elevon jammed at $-15^{\circ}$ (left side control surfaces).
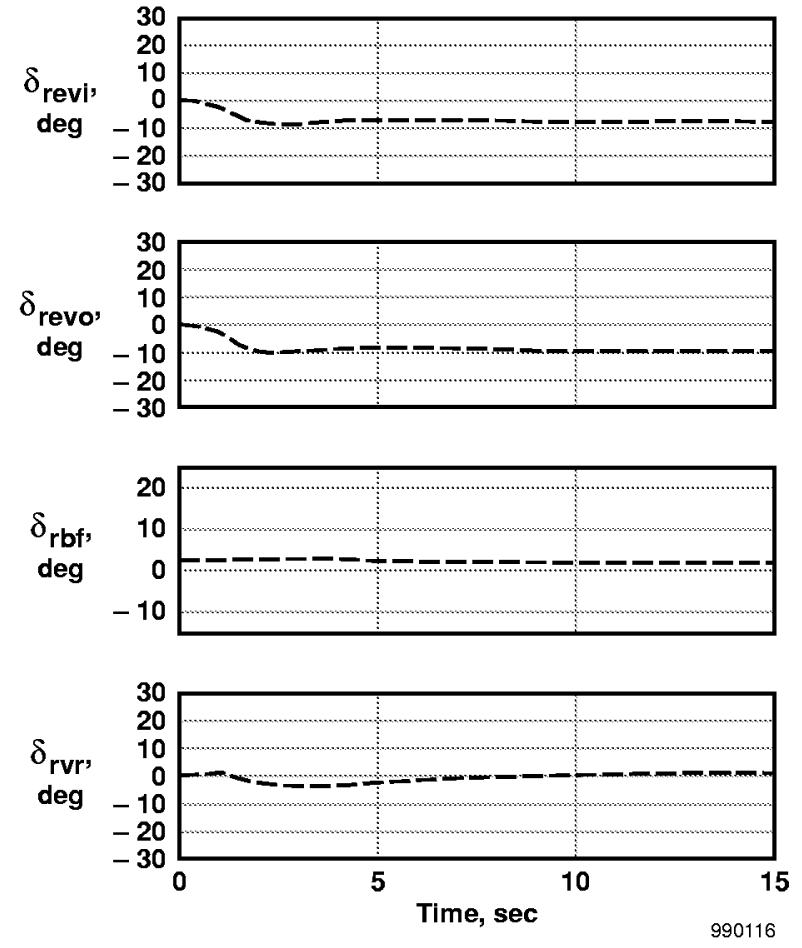

Figure 4. X-33 surface deflections using the PI-servo method with left inboard elevon jammed at $-15^{\circ}$ (right side control surfaces). 
As shown in figures 2-4, the PI-servo control approach is found to work well for an elevon jammed at $-15^{\circ}$. Figures 5-7 show how well the PI-servo controller with the failure works compared to the nominal controller without a failure. Note that the nominal controller with an elevon jammed at $-15^{\circ}$ is unstable and departs very soon after the failure, and as such is not plotted. In further studies, the PI-servo control approach worked well for any of the six aerosurfaces except the flaps. The flap PI-servo results are not presented in this paper because of length constraints.
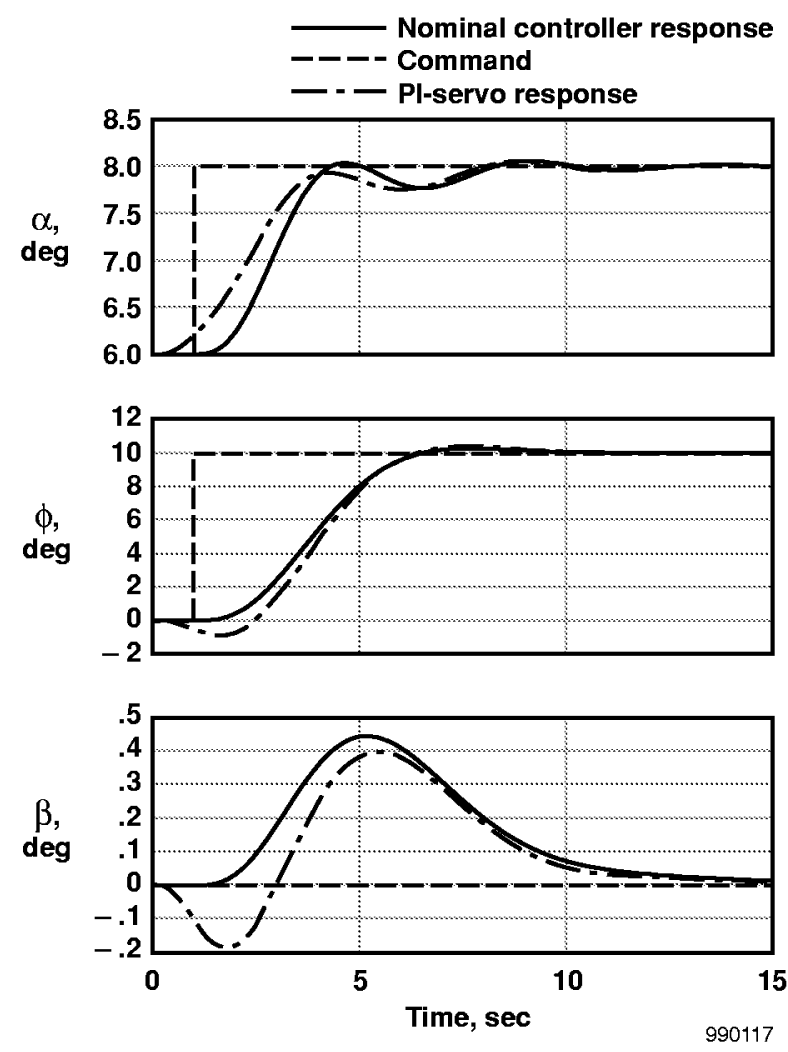

Figure 5. Comparison response using the PI-servo method with left inboard elevon jammed at $-15^{\circ}$ and the nominal controller without a failure.

For the jamming of one of the flaps not far from the nominal trim position, the PI-servo control system performs well. Only when a flap is jammed at a position near its limits of retrimmable range does the performance of the reconfigured PI-servo control system begin to degrade considerably.
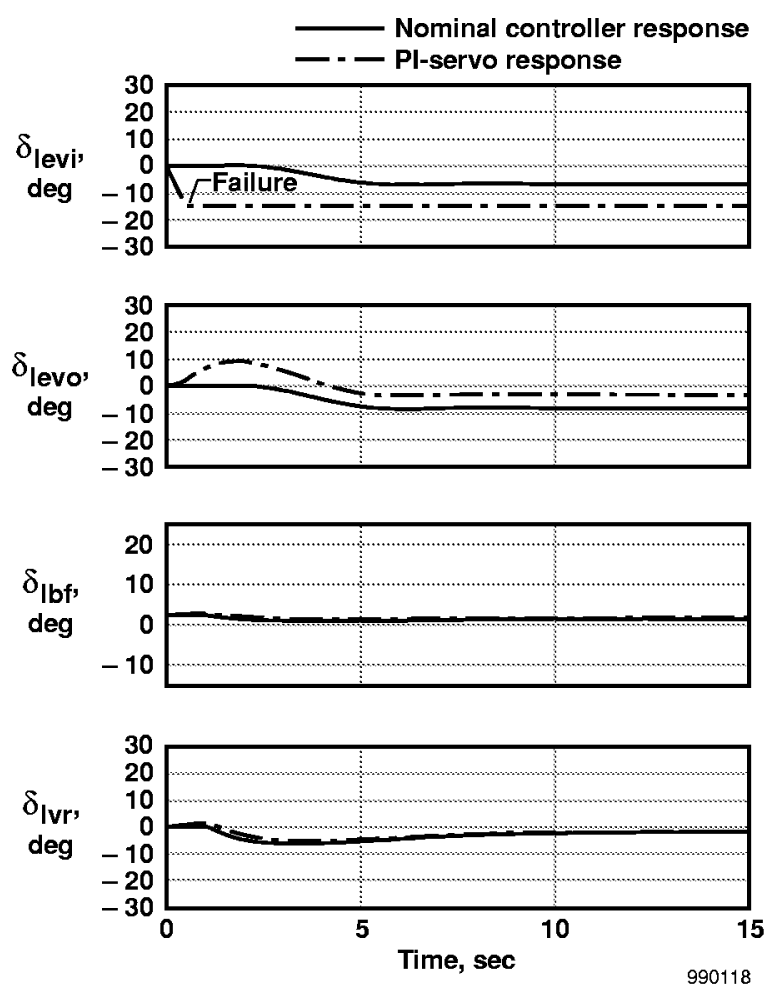

Figure 6. Comparison response using the PI-servo method with left inboard elevon jammed at $-15^{\circ}$ and the nominal controller without a failure (left side control surfaces).

\section{Control-Allocation Design Results}

Figures 8-10 show comparisons of the CA method and the PI-servo approach for the case where the right body flap is jammed at $-5^{\circ}$. Figure 8 shows the angleof-attack, roll angle, and sideslip angle response; figures 9 and 10 show the aerosurface positions using the two methods. Again, the examples presented are for simultaneous tracking of angle-of-attack and roll angle commands during the failure. Figures 11-13 show the comparison of the responses for a right body flap jammed at $5^{\circ}$ under the $\mathrm{CA}$ and PI-servo control approaches, respectively. These two cases show what happens when the same surface fails but in opposite directions.

The comparisons are noteworthy, particularly in longitudinal $(\alpha)$ response, where the jammed flap causes significant overshoot/undershoot in angle of attack under the PI-servo controller. Conversely, the CA 

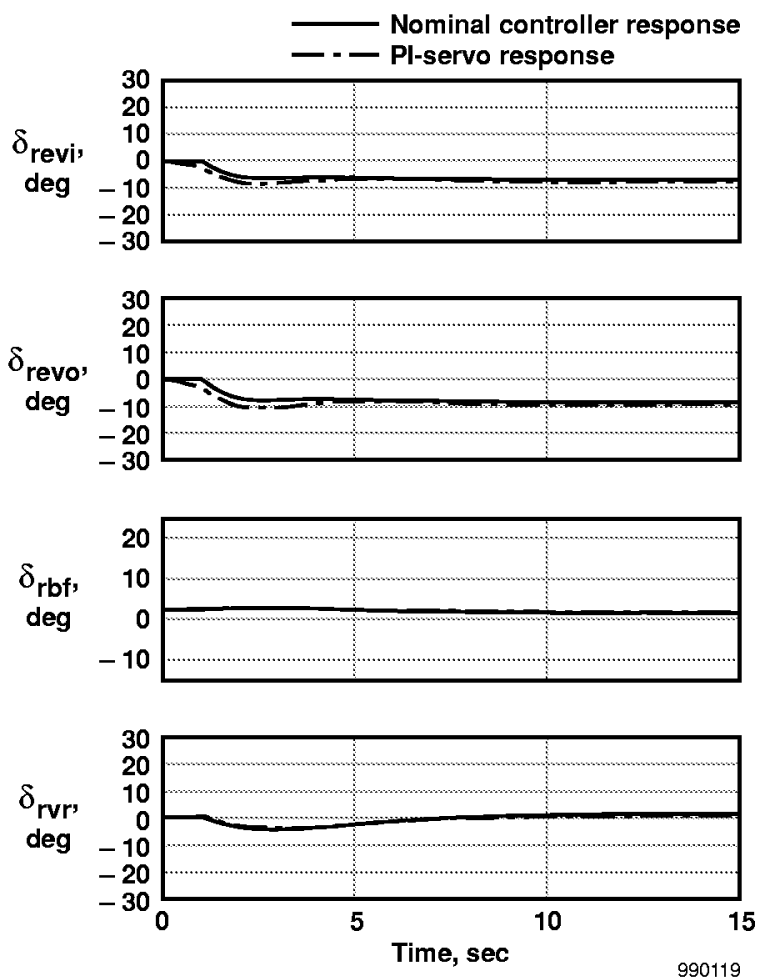

Figure 7. Comparison response using the PI-servo method with left inboard elevon jammed at $-15^{\circ}$ and nominal controller without a failure (right side control surfaces).
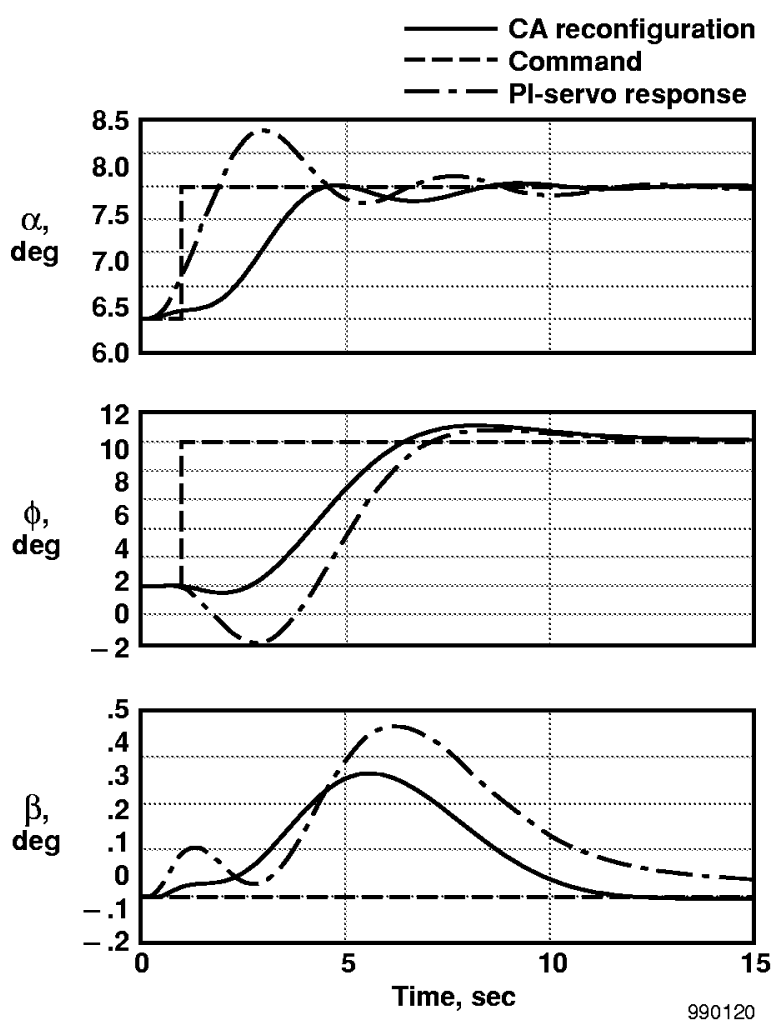

Figure 8. Response with jammed right body flap, $\delta_{r b f}=-5^{\circ}$.
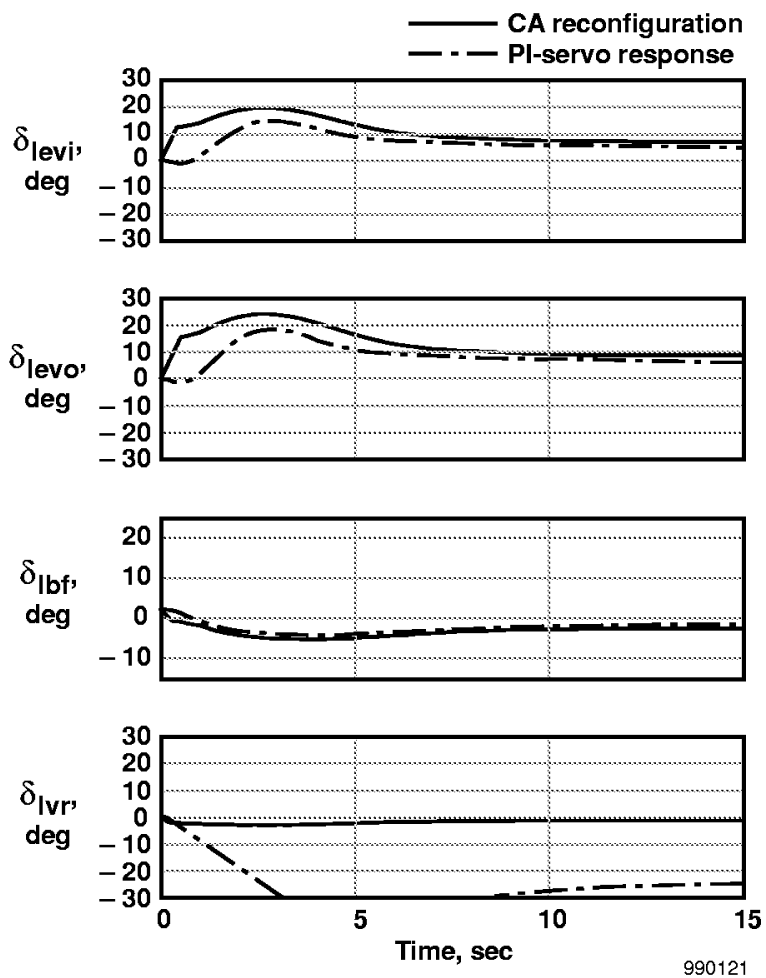

Figure 9. Comparison response using the PI-servo method with right body flap jammed at $-5^{\circ}$ (left side control surfaces).
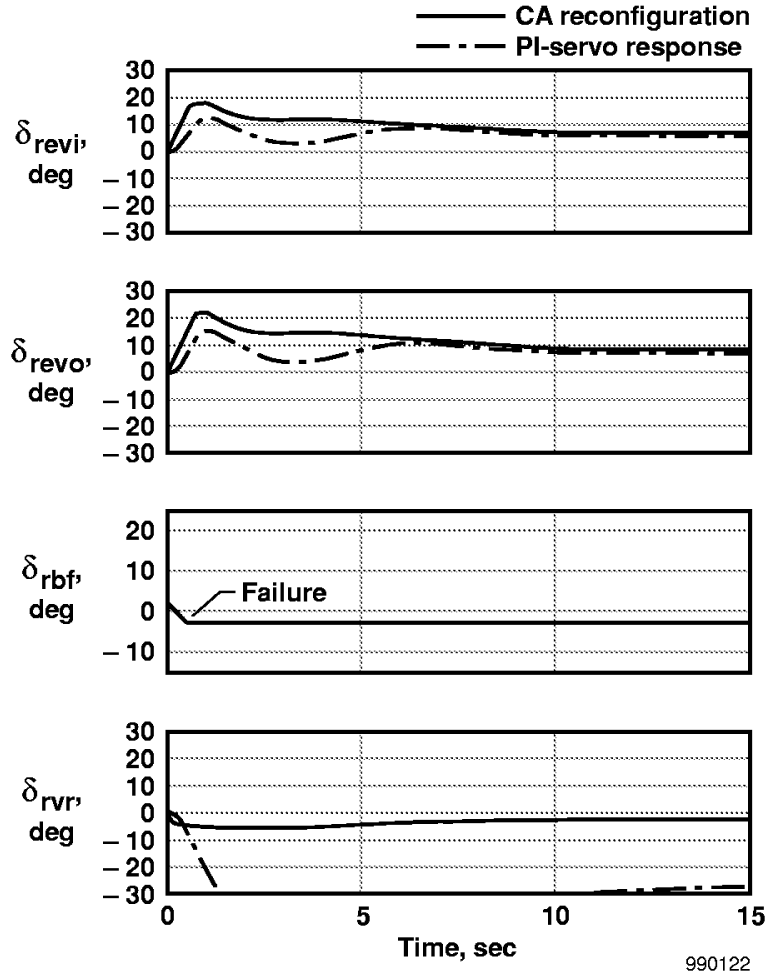

Figure 10. Comparison response using the PI-servo method with right body flap jammed at $-5^{\circ}$ (right side control surfaces). 

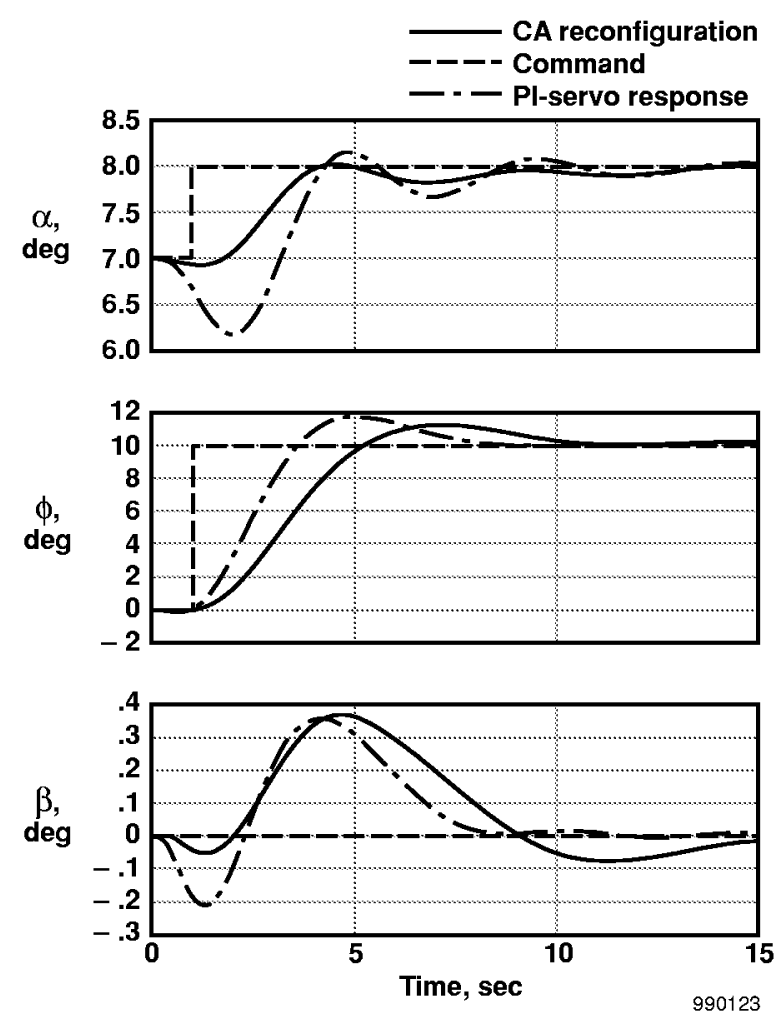

Figure 11. Response with jammed right body flap, $\delta_{r b f}=5^{\circ}$.
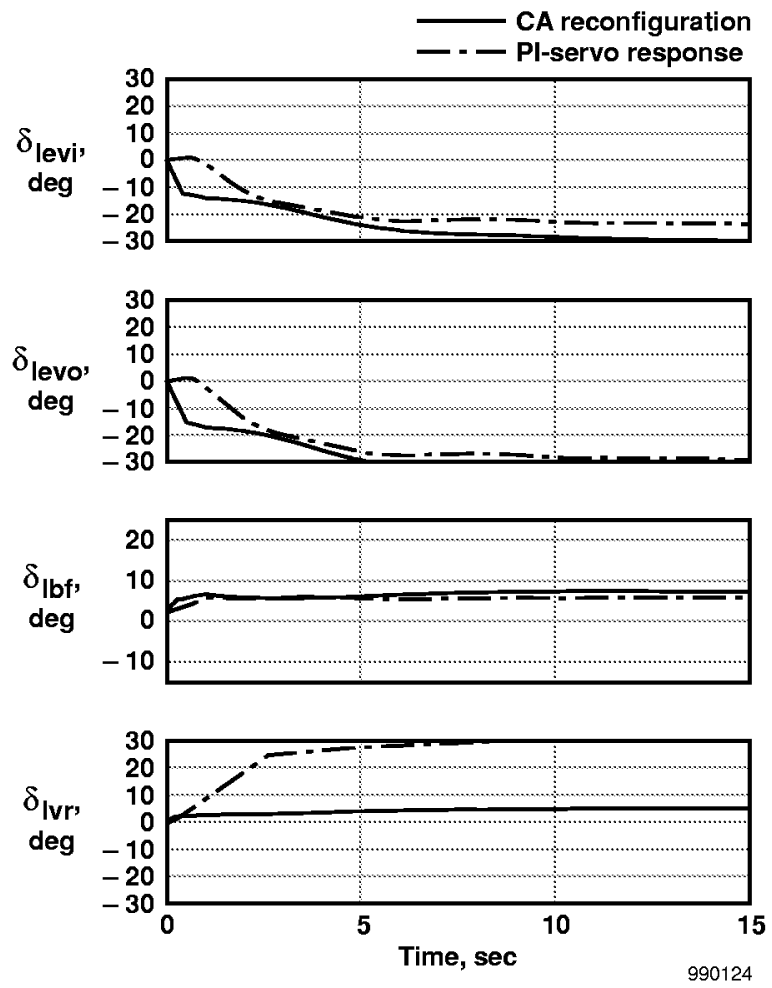

Figure 12. Comparison response using the PI-servo method with right body flap jammed at $5^{\circ}$ (left side control surfaces).
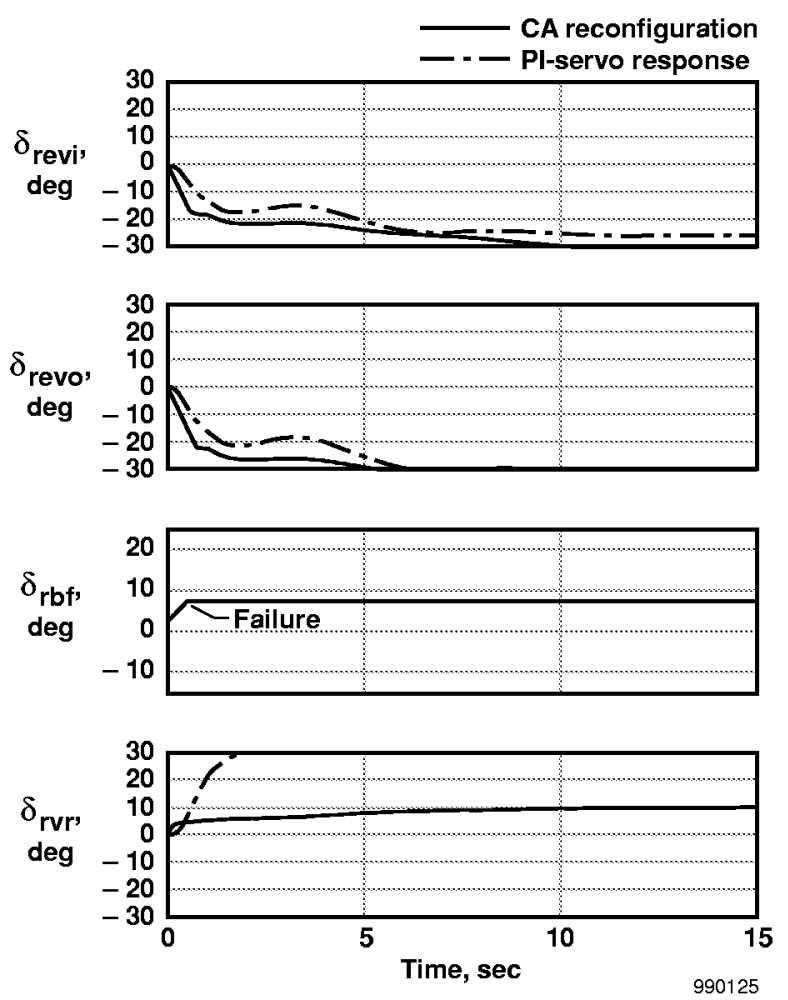

Figure 13. Comparison response using the PI-servo method with right body flap jammed at $5^{\circ}$ (right side control surfaces).

approach still provides a good response in these difficult cases. The CA reconfiguration responses (figs. 8 and 11) for the two different failures are very similar

The CA approach was found to provide uniformly good performances for all the failure (jamming) cases in which stabilization and command tracking are possible with the remaining aerosurfaces. In the challenging situations where a body flap is a runaway and jammed, the CA approach yields a similar good performance for any jammed position of a body flap in the incremental range of $\left[-8^{\circ}, 8^{\circ}\right]$. When the flap jammed position is outside this range, the performance deteriorates rapidly and eventually instability occurs because some of the remaining operable surfaces become severely saturated when trying to counter the jammed flap. On a side note, investigation of the failed time histories and the control surface positions shows that when a surface fails, its companion surface seems to be offset to approximately the same position. 


\section{Concluding Remarks}

Two methods for design of reconfigurable flight control systems have been presented. One method is based on a robust servomechanism design (PI-servo) methodology. For the failure cases involving a jammed surface, the robust servomechanism approach leads to a multiple input-multiple output proportional-plusintegral control system. The other method uses a control-allocation (CA) scheme to redistribute the operable control surfaces to cancel the influence of the jammed surface and still provide desired control moments and forces to the aircraft. A globally convergent, simple, fixed-point algorithm is developed for onboard implementation of the method. Applications of both approaches to reconfigurable entry flight control of the X-33 vehicle demonstrate the potential of the two methods. Although the first method is the simpler of the two, the second method appears to offer uniformly good performance at a cost of requiring slightly higher computation. All of the examples presented demonstrate the ability of both methods to stabilize the vehicle and provide adequate response to simultaneous angle-ofattack and roll angle commands. 


\section{Appendix \\ Linearized Model of the X-33 Vehicle}

The following is a linearized model of the $\mathrm{X}-33$ vehicle near the terminal area energy management interface in entry flight. The flight conditions are: weight $=78,593 \mathrm{lbm}$, height $=97,167 \mathrm{ft}$, speed $=$ Mach 3.13, trim angle of attack $=6.23^{\circ}$, trim $=0.922^{\circ}$, and trim roll angle $=$ trim sideslip angle $=0$. Let

$$
\mathrm{u}=\left(\delta_{r e v i} \delta_{l e v i} \delta_{r b f} \delta_{l b f} \delta_{r v r} \delta_{l v r} \delta_{r e v o} \delta_{l e v o}\right)^{T}
$$

be the control surface perturbations from the trim values, where

$$
\begin{aligned}
& \delta_{r e v i}, \delta_{l e v i}=\text { right and left inboard elevons; } \\
& \delta_{r b f}, \delta_{l b f}=\text { right and left body flaps; } \\
& \delta_{r i r}, \delta_{l v r}=\text { right and left rudders; and } \\
& \delta_{r e v o}, \delta_{l e v o}=\text { right and left outboard elevons. }
\end{aligned}
$$

All the control surface deflections are in degrees. The surface trim values are $2.4552^{\circ}$ for the body flaps, $0.0^{\circ}$ for the inboard and outboard elevons, and $0^{\circ}$ for the rudders. Let the perturbations from the trim conditions be $\mathrm{x}=(\mathrm{p} r \beta \phi \varphi \alpha \mathrm{q} \theta v)^{T}$, where the standard notation and English system are used for the aircraft state. The linearized dynamics of the $\mathrm{X}-33$ vehicle at the above flight conditions are given by

$$
\dot{\mathrm{x}}=\mathbf{A x}+\mathbf{B u},
$$

where

$$
\mathbf{A}=10^{-3} \times\left[\begin{array}{cc}
\mathbf{A}_{\text {lat }} & 0 \\
0 & \mathbf{A}_{\text {lon }}
\end{array}\right]
$$

with

$$
\mathbf{A}_{\text {lat }}=\left[\begin{array}{ccccc}
-96.95 & 28.11 & 673.08 & 0 & 0 \\
4.42 & -34.78 & -936.95 & 0 & 0 \\
-0.019 & -999.94 & -36.18 & 10.27 & -0.95 \\
10^{3} & 0 & 0 & 0 & 0 \\
0 & 10^{3} & 0 & 0 & 0
\end{array}\right],(\mathrm{A}-4)
$$

$$
\mathbf{A}_{\text {lon }}=\left[\begin{array}{cccc}
-70.55 & 1000.29 & 0.954 & 0.038 \\
-1546.31 & -52.24 & 0 & -0.046 \\
0 & 10^{3} & 0 & 0 \\
-550.04 & 0 & -559.09 & -13.375
\end{array}\right]
$$

and

$$
\mathbf{B}=\left[\begin{array}{cccccccc}
-0.2137 & 0.2137 & -0.8418 & 0.8418 & 0.0115 & 0.0115 & -0.2612 & 0.2621 \\
0.0448 & -0.0448 & 0.3639 & -0.3639 & -0.0077 & -0.0077 & 0.0548 & -0.0548 \\
-0.0001 & 0.0001 & 0.0003 & -0.0003 & 0 & 0 & -0.0002 & 0.0002 \\
0 & 0 & 0 & 0 & 0 & 0 & 0 & 0 \\
0 & 0 & 0 & 0 & 0 & 0 & 0 & 0 \\
-0.0003 & -0.0003 & -0.0017 & -0.0017 & 0.000004 & -0.000004 & -0.0004 & 0.0004 \\
-0.0617 & -0.0617 & -0.5393 & -0.5393 & 0.0050 & -0.0050 & -0.0754 & 0.0754 \\
0 & 0 & 0 & 0 & 0 & 0 & 0 & 0 \\
-0.0034 & -0.0034 & -0.1285 & -0.1285 & 0.0011 & -0.0011 & -0.0041 & -0.0041
\end{array}\right]
$$




\section{$\underline{\text { References }}$}

${ }^{1}$ Wagner, Elaine A., John J. Burken, Curtis E. Hanson, and Jerry M. Wohletz, "Deterministic Reconfigurable Control Design for the X-33 Vehicle," AIAA-98-4413, Aug. 1998.

${ }^{2}$ Brinker, Joseph S. and Kevin A. Wise, "Reconfigurable Flight Controls for a Tailless Advanced Fighter Aircraft,” AIAA-98-4107, Aug. 1998.

${ }^{3}$ Monaco, J., D. Ward, R. Barron, and R. Bird, "Implementation and Flight Test Assessment of an Adaptive, Reconfigurable Flight Control System," AIAA-97-3738, Aug. 1997.

${ }^{4}$ Desoer, C. A. and Y. T. Wang, "Linear Time-Invariant Robust Servomechanism Problem: A Self-Contained Exposition," Control and Dynamic Systems, C. T. Leondes, ed., vol. 16, Academic Press, New York, 1980, pp. 81-129.
${ }^{5}$ E. J. Davison, “The Robust Control of a Servomechanism Problem for Linear Time-Invariant Multivariable Systems," IEEE Transactions on Automatic Control, vol. AC-21, no. 1, Feb. 1976, pp. 25-34.

${ }^{6}$ Enns, Dale, "Control Allocation Approaches," AIAA-98-4109, Aug. 1998.

${ }^{7}$ Luenberger, David G., Linear and Nonlinear Programming, second edition, Addison-Wesley Publishing Company, Reading, Massachusetts, 1984, pp. $425-426$.

${ }^{8} \mathrm{Lu}$, P. "Constrained Tracking Control of Nonlinear Systems," Systems \& Control Letters, vol. 27, no. 5, 1996, pp. 305-314.

${ }^{9}$ Anon., "Simulink $\left.{ }^{(}\right)$: Dynamic System Simulation Software User's Guide," The MathWorks Inc., Natick, Massachusetts, Dec. 1993. 
Public reporting burden for this collection of information is estimated to average 1 hour per response, including the time for reviewing instructions, searching existing data sources, gathering and maintaining the data needed, and completing and reviewing the collection of information. Send comments regarding this burden estimate or any other aspect of this collection of information, including suggestions for reducing this burden, to Washington Headquarters Services, Directorate for Information Operations and Reports, 1215 Jefferson Davis Highway, Suite 1204, Arlington, VA 22202-4302, and to the Office of Management and Budget, Paperwork Reduction Project (0704-0188), Washington, DC 20503.

1. AGENCY USE ONLY (Leave blank)

\section{REPORT DATE}

August 1999

\section{REPORT TYPE AND DATES COVERED}

Technical Memorandum

4. TITLE AND SUBTITLE

Reconfigurable Flight Control Designs With Application to the X-33

Vehicle

6. AUTHOR(S)

WU 242-33-02-00-23-00-TA5

John J. Burken, Ping Lu, and Zhenglu Wu

7. PERFORMING ORGANIZATION NAME(S) AND ADDRESS(ES)

NASA Dryden Flight Research Center

P.O. Box 273

Edwards, California 93523-0273

8. PERFORMING ORGANIZATION

REPORT NUMBER

H-2345

9. SPONSORING/MONITORING AGENCY NAME(S) AND ADDRESS(ES)

10. SPONSORING/MONITORING AGENCY REPORT NUMBER

National Aeronautics and Space Administration

Washington, DC 20546-0001

NASA TM-1999-206582

11. SUPPLEMENTARY NOTES

Presented at AIAA Guidance Navigation and Control Conference, Portland, Oregon, August 9-11, 1999, AIAA-99-4134.

12a. DISTRIBUTION/AVAILABILITY STATEMENT

12b. DISTRIBUTION CODE

Unclassified-Unlimited

Subject Category 08

13. ABSTRACT (Maximum 200 words)

Two methods for control system reconfiguration have been investigated. The first method is a robust servomechanism control approach (optimal tracking problem) that is a generalization of the classical proportional-plus-integral control to multiple input-multiple output systems. The second method is a controlallocation approach based on a quadratic programming formulation. A globally convergent fixed-point iteration algorithm has been developed to make onboard implementation of this method feasible. These methods have been applied to reconfigurable entry flight control design for the X-33 vehicle. Examples presented demonstrate simultaneous tracking of angle-of-attack and roll angle commands during failures of the right body flap actuator. Although simulations demonstrate success of the first method in most cases, the control-allocation method appears to provide uniformly better performance in all cases.

Failure control system design, Reconfigurable flight controls, Robust servomechanism design

17. SECURITY CLASSIFICATION OF REPORT

Unclassified

18. SECURITY CLASSIFICATION
OF THIS PAGE
Unclassified

Unclassified
15. NUMBER OF PAGES

21

16. PRICE CODE

A03

19. SECURITY CLASSIFICATION OF ABSTRACT

Unclassified
20. LIMITATION OF ABSTRACT

Unlimited 